\title{
Modeling undesirable factor in efficiency assessment of agricultural sector within EU-27 countries and over a time period
}

\author{
Seyyed Hassan Pishgar-Komleh ${ }^{1 *^{*}}$, Lukáš Čechura $^{1 \S}$, Elena Kuzmenko ${ }^{1 \dagger}$ \\ ${ }^{1}$ Department of Economics, Faculty of Economics and Management, Czech University of Life Science in \\ Prague, Czech Republic.
}

\begin{abstract}
Agriculture plays an important role in economy influencing both society and environment due to its crucial contribution to food security, employment opportunities and climate change. According to the energy and climate policy framework, the target for 2030 is reduction of $40 \%$ of greenhouse gas (GHG) emissions in the European Union without any decline in productivity of production. One critical challenge in assessing the productivity is involving the undesirable outputs a long with a series of time. This approach essentially requires applying new management methods. In this study we applied a slack based measurement (SBM) of efficiency in the presence of undesirable outputs in a window data envelopment analysis (WDEA) framework to evaluate the crop production sector of $27 \mathrm{EU}$ countries. The required data consisting the average input costs $\left(€ \mathrm{ha}^{-1}\right)$ (including fertilizer, protection, seed and other costs as the model inputs), the gross domestic product ( $€ \mathrm{ha}^{-1}$ ) and the total GHG emissions $\left(\mathrm{kg} \mathrm{CO}_{2 \text {-eq }} \mathrm{ha}^{-1}\right)$ as the model desirable and undesirable outputs were collected from FADN and Eurostat databases. To indicate the ideal window width, the efficiency scores of ten window data envelopment analysis (WDEA) models were evaluated. Obtained results showed the highest efficiency scores for Spain, Greece, Italy and Malta. To compare the proposed model with the conventional ones, the results of a SBM-WDEA incorporated with undesirable outputs have been compared with a SBM-WDEA model without undesirable output and a SBM-DEA model with undesirable output and without window analysis. The results advocate in favor of the new model, showing promise for its better performance.
\end{abstract}

Keywords: Agriculture; Europe; Productivity; SBM with undesirable; Window-DEA. 


\section{$2^{\text {nd }}$ International Conference on}

\section{MANAGEMENT, ECONOMICS \& FINANCE}

\section{5-17 November 2019}

\section{Introduction}

Agriculture plays an important role in the economy and society due to high contribution to food security, employment opportunities and etc. Besides these roles, agriculture contributes to the climate change by generating Greenhouse Gases (GHGs). Total anthropogenic GHG emissions show the continuous growth since 2000. However, most estimates show a decline of GHG emissions for Agriculture, Forestry and Other Land Use (AFOLU) sector (Edenhofer et al., 2014). AFOLU as the main sector for food security and sustainable development accounts for about $24 \%$ of the total GHG emissions (Edenhofer et al., 2014). According to the energy and climate policy framework, the target for 2030 is to achieve a reduction of GHG emissions to 40\% (European Commission, 2014). Besides this environmental goals, one of the main long-term goals for the European Union (EU) agriculture is supporting farmers to improve agricultural productivity in all EU countries (European Commission, 2013). Therefore, the performance of agricultural sector in EU needs to be monitored and improved. To evaluate the performance, the input-output efficiency can be measured through parametric and non-parametric methods. Compared to the parametric method, non-parametric method does not require any function to estimate the unknown variables. This method applies a set of minimum possible combination of inputs and outputs a long with evaluation of all Decision Making Units (DMUs) (Lin, Sun, Marinova, \& Zhao, 2018). Data Envelopment Analysis (DEA) as the most popular non-parametric method is a management tool to estimate the efficiency of DMUs.

Agricultural productivity and efficiency assessment in the EU was the subject of many research (Baráth \& Fertö, 2017; Peças, Götze, Bravo, Richter, \& Ribeiro, 2019; Rizov, Pokrivcak, \& Ciaian, 2013; Rungsuriyawiboon \& Lissitsa, 2007). The most common types of DEA models in agriculture are restricted to the cross-sectional data. Although cross-sectional data indicate the performance of DMUs, the panel data (data over multiple time periods) provide more reliable performance due to tracking the DMU performance through a sequence of time periods (Kumbhakar \& Lovell, 2003). George Vlontzos, Niavis, and Manos (2014) applied a non-radial DEA model to estimate the agricultural energy and environmental efficiency of EU-25 countries during 2001 and 2008. They applied average efficiency values to compare different years. To handle both cross-sectional and time series data and provide the efficiency trends over time, Charnes and Cooper (1984) developed a window DEA (WDEA) model. Sardar Shahraki, Ali Ahmadi, and Safdari (2018) applied a WDEA model without considering undesirable outputs to assess the productivity changes of wheat production during 2014 and 2016. Similarly, Masuda (2018) evaluated the energy efficiency of different scale of rice farming between 2005 and 2011 without treating the undesirable outputs in a WDEA model. Results indicated that by increasing the scale of rice farming, energy efficiency improved. G. Vlontzos and Pardalos (2017) evaluated the GHG emissions efficiency of agriculture sector in EU-25 countries during 2006 and 2012. They applied a non-radial WDEA model (a window with 3 years width) and applied a translation vector to treat the undesirable output in the model. An issue that has received very little attention in WDEA is the appropriate window width. The window width is the number of years included 


\section{$2^{\text {nd }}$ International Conference on}

\section{MANAGEMENT, ECONOMICS \& FINANCE}

\section{5-17 November 2019}

in a WDEA model. G. Vlontzos and Pardalos (2017), Al-Refaie, Hammad, and Li (2016) and Asmild, Paradi, Aggarwall, and Schaffnit (2004) declared that the window width should be large enough to provide adequate sample size while it should be as small as possible to prevent unfair comparisons. With respect to this fact that the window width would have impact on the efficiency score of DMUs, applying a method to determine the ideal width is essential. Lin et al. (2018) proposed and applied a method as a solution for this problem. Regarding to this fact that agriculture sector consists of two different livestock and crop subsectors, in

order to have a more accurate productivity assessment, it is essential to distinguish these two sub-sectors. Therefore, the focus of this study was on crop production. Also this study was aimed at improving previous models by applying a new WDEA model which treats undesirable outputs more precisely. Moreover, we aimed to compare the new model with the conventional models.

\section{Methods}

In this section, the databases used in this study are presented, afterward, an input-oriented WDEA model with slack based measurement of efficiency with undesirable outputs is described to evaluate the crop production sector of EU-27 countries during 2008-2017. In addition, the method for determining the ideal window width is expressed.

\subsection{Data inventory}

To obtain required data for WDEA, the panel data including monetary data and total GHG emissions for agriculture sector of 27 EU countries during 2004 and 2017 were collected from two main databases. As it was discussed in previous section, regarding to this fact that agriculture sector consists of livestock and crop sub-sectors, and since the focus of this study was on productivity assessment of crop production sector, data related to the crop production were included in this study. Monetary data including the Gross Domestic Product (GDP) and the detailed cost data (including fertilizer, protection, seed and other costs) for EU countries were extracted from the Farm Accountancy Data Network (FADN) database (FADN, 2019). FADN is an European system of sample surveys conducted to collect annual accountancy data from farms for $28 \mathrm{EU}$ countries. Due to lack of data, Croatia was excluded from analysis and data for Bulgaria and Portugal during 2004 and 2006 were estimated by the linear regression based on the subsequent years. The monetary data were calculated per hectare for the corresponding years and countries. Data of total GHG emissions related to crop production for EU-27 during 2004 and 2017 were extracted from European Statistical Office (Eurostat) (Eurostat, 2019). Eurostat is the statistical office of the EU, provides high-quality agricultural statistics in Europe. In this database, total GHG emissions were calculated per hectare for the corresponding years and countries. Because of missing data, total GHG emission value for Italy in 2009 and 2017 were estimated by a linear regression over other years. 


\section{$2^{\text {nd }}$ International Conference on}

\section{MANAGEMENT, ECONOMICS \& FINANCE}

\section{5-17 November 2019}

\subsection{Window DEA analysis}

DEA as a nonparametric technique applies linear programming technique to calculate the relative efficiency of a DMU comparing to other DMUs (Emrouznejad \& Yang, 2018). The objective of a DEA model is maximizing the efficiency which is defined as the ratio of outputs over inputs with regard to the constraint of equal to and less than unity of technical efficiency (Mustapha, Aziz, \& Hashim, 2013). Technical efficiency is measured based on radial and non-radial methods (Cooper, Seiford, \& Tone, 2007). As an advantage, compared to the radial DEA models, the non-radial models concern the changes of inputs and outputs with considering slacks. The slacks are defined as the difference between the inputs surplus and the outputs shortage. Therefore, we applied a non-radial method for DEA analysis and the efficiency scores were measured are known as the slacks-based measurement of efficiency (SBM). Based on the main classification, DEA models are classified into constant returns to scale (CRS) (Charnes, Cooper, \& Rhodes, 1978) and variable returns to scale (VRS) models (Banker, Charnes, \& Cooper, 1984). CRS (also called CCR) assumes a constant change in outputs as a result of input changes while

VRS (also called BCC) assumes a variable change in outputs due to input changes. We applied a CRS in our study. Depending on whether the efficiency improvement in a DEA model is based on reducing the inputs level while outputs level are assumed fixed or increasing the outputs level while inputs level are constant, a DEA model is divided into an input or output-oriented DEA model (Charnes et al., 1978). Regarding to this fact that in agricultural activities, producers have more control over inputs rather that outputs, an input-oriented model was applied in this study.

In the WDEA introduced by Charnes and Cooper (1984), each DMU in a particular year is treated as a particular DMU and its performance is evaluated and compared to its performance in other years and against other DMUs over time (Lin et al., 2018). Therefore, in a WDEA model, efficiency score of each DMU $(n=1,2, \ldots, N)$ with $m$ inputs and $s$ outputs (desirable and undesirable outputs) is estimated over $T(t=1,2, \ldots, T)$ periods. Assuming $X_{n}^{t}$ and $Y_{n}^{t}$ as the input and output vectors, the inputs and outputs corresponding to a particular DMU in a particular year is expressed as follows:

$$
X_{n}^{t}=\left[\begin{array}{c}
X_{n}^{1 t} \\
\vdots \\
x_{n}^{m t}
\end{array}\right], Y_{n}^{t}=\left[\begin{array}{c}
Y_{n}^{1 t} \\
\vdots \\
x_{n}^{s t}
\end{array}\right]
$$

Assuming that windows are started at time $k(1, \ldots, T)$ and a window width is $w(1, \ldots, T-k)$, inputs and outputs are displayed as follows:

$$
X_{k w}=\left[\begin{array}{cccc}
x_{1}^{k} & x_{2}^{k} & \ldots & x_{N}^{k} \\
x_{1}^{k+1} & x_{2}^{k+1} & \ldots & x_{N}^{k+1} \\
\vdots & \vdots & \ddots & \vdots \\
x_{1}^{k+w} & x_{w}^{k+w} & \ldots & x_{N}^{k+w}
\end{array}\right] \text { and } Y_{k w}=\left[\begin{array}{cccc}
Y_{1}^{k} & Y_{2}^{k} & \ldots & Y_{N}^{k} \\
Y_{1}^{k+1} & Y_{2}^{k+1} & \ldots & Y_{N}^{k+1} \\
\vdots & \vdots & \ddots & \vdots \\
Y_{1}^{k+w} & Y_{w}^{k+w} & \ldots & Y_{N}^{k+w}
\end{array}\right]
$$

Applying these matrices into a DEA model leads to the results of WDEA. 


\section{$2^{\text {nd }}$ International Conference on}

\section{MANAGEMENT, ECONOMICS \& FINANCE}

\section{5-17 November 2019}

The most challenging issue in DEA is treating undesirable outputs in the efficiency assessment. Several approaches have been introduced, developed and applied to solve this issue including i) treating undesirable outputs as inputs (Dyckhoff \& Allen, 2001), ii) data transformation (Golany \& Roll, 1989), iii) impact rate (You \& Yan, 2011), iv) ratio model (You \& Yan, 2011), v) SBM-DEA incorporated with undesirable outputs, and etc. According to the findings of a research conducted by Pishgar-komleh, Zylowski, Rozakis, and Kozyra (2019) for comparing the specified approaches, it was illustrated that among these approaches, the SBM-DEA incorporated with undesirable outputs can reflect the performance of DMUs properly. The SBM model with undesirable outputs was proposed by Cooper et al. (2007) to treat both desirable and undesirable outputs in the DEA models as separate variables. Therefore, an efficient DMU is determined as the one with more desirable $\left(Y^{g}\right)$ and less undesirable outputs $\left(Y^{b}\right)$ (relative to less inputs $\left.(X)\right)$. The slacks for inputs, desirable and undesirable outputs are defined as $s^{-}, s^{g}, s^{b}$ and respectively. The SBM with undesirable outputs is presented as:

$$
\begin{array}{ll}
\text { Minimize } & \rho^{*}=\frac{1-\frac{1}{m} \sum_{i=1}^{m} \frac{s_{i}^{-}}{x_{i 0}}}{1+\frac{1}{s_{1}+s_{2}}\left(\sum_{r=1}^{s 1} \frac{s_{r}^{g}}{y_{r 0}^{g}}+\sum_{r=1}^{s 2} \frac{s_{r}^{b}}{y_{r 0}^{b}}\right)} \\
\text { Subject to: } & x_{0}=X \lambda+s^{-} ; y_{0}^{g}=Y^{g} \lambda-s^{g} ; y_{0}^{b}=Y^{b} \lambda+s^{b} \\
& s^{-} \geq 0, \quad s^{g} \geq 0, \quad s^{b} \geq 0, \quad \lambda \geq 0
\end{array}
$$

By transferring Eq. 3 into a linear programing problem, Eq. 3 is displayed as follows:

$$
\begin{array}{ll}
\text { Minimize } & \tau^{*}=\min t-\frac{1}{m} \sum_{i=1}^{m} \frac{s_{i}^{-}}{x_{i 0}} \\
\text { Subject to: } & 1=t+\frac{1}{s_{1}+s_{2}}\left(\sum_{r=1}^{s_{1}} \frac{s_{r}^{g}}{y_{r 0}^{g}}+\sum_{r=1}^{s_{2}} \frac{s_{r}^{b}}{y_{r 0}^{b}}\right) \\
& x_{0} t=X \Lambda+S^{-} ; y_{0}^{g} t=Y^{g} \Lambda-S^{g} ; y_{0}^{g b}=Y^{b} \lambda+S^{b} \\
& S^{-} \geq 0, \quad S^{g} \geq 0, \quad S^{b} \geq 0, \quad \Lambda \geq 0, \quad t>0
\end{array}
$$

If the optimal solution of linear programming are $t^{*}, \Lambda^{*}, S^{-*}, S^{g *}, S^{b *}$, then the optimal solution of SBM-undesirable will be $\rho^{*}=\tau^{*}, \lambda^{*}=\Lambda^{*} / t^{*}, \mathrm{~s}^{-*}=S^{-*} / t^{*}, s^{g *}=$ $S^{g *} / t^{*}, S^{b *}=s^{b *} / t^{*}$.

According to the Eqs.1-4, the model opted to measure the performance of $27 \mathrm{EU}$ countries was a SBM-WDEA incorporated with undesirable outputs. To decrease the amount of analysis and calculation, a ten year period (2008-2017) was considered for window analysis. Each country was considered as a particular DMU in each year. Thus, the total number of DMUs were 270 ( 27 countires $\times 10$ years). The inputs in the WDEA model were determined as the average costs of fertilizer, protection, seed and other costs $\left(€ \mathrm{ha}^{-1}\right)$ for the crop production system of EU countries. The desirable and undesirable outputs were the average GDP $\left(€ \mathrm{ha}^{-1}\right)$ and GHG emissions $\left(\mathrm{kg} \mathrm{CO}_{2 \text {-eq }} \mathrm{ha}^{-1}\right)$, respectively. As it has been discussed previously, in most WDEA (Al-Refaie et al., 2016; Řepková, 2014; G. Vlontzos \& Pardalos, 2017), the window width is often being chosen subjectively and arbitrary. To determine the ideal window width, Eqs.(5)-(7) were applied as follows (Lin et al., 2018):

$$
D e v_{i j}=\frac{E F_{i j}-A V_{i j}}{A V_{i j}} \times 100
$$




\section{$2^{\text {nd }}$ International Conference on}

\section{MANAGEMENT, ECONOMICS \& FINANCE}

$$
\begin{array}{cc}
\text { 15-17 November } 2019 \\
U_{i j}=\left\{\begin{array}{cc}
1 & \text { when }\left|\operatorname{Dev}_{i j}\right|=\min _{1 \leq j \leq T}\left(\left|\operatorname{Dev}_{i j}\right|\right) \\
0 & \text { when }\left|\operatorname{Dev}_{i j}\right| \neq \min _{1 \leq j \leq T}\left(\left|\operatorname{Dev}_{i j}\right|\right)
\end{array}\right. \\
C_{j}=\sum_{i=1}^{T} U_{i j} & \text { Eq. } 6
\end{array}
$$

where $E F_{i j}$ is the average efficiency of all countries in year $i$ and window width $j, A V_{i g}$ represents the average of $E F_{i j}$ in period $i$ and $D e v_{i j}$ denotes the deviation of $E F i j$ and $A V_{i g}$. By using Eq.5 and Eq.6, the ideal width is the $j$ in which $C_{j}$ is maximum.

All inputs and outputs (desirable and undesirable) were applied in a SBM-WDEA model incorporated with undesirable outputs and the efficiency score of all countries were estimated for

all window widths $(\mathrm{w}=1, \ldots, T)$. Then the ideal window width was calculated by applying Eqs.5-7 and the inter-country evaluation was conducted. Finally, the results of applied model were compared with the results of two conventional models including a SBM-WDEA model without undesirable output (model 2) and a SBM-DEA model incorporated with undesirable outputs without window analysis (model 3). The model was developed by Excel 2016, Matlab 2015b and DeaSolverPro15 programs.

\section{Results and discussion}

In this section the obtained results are presented and discussed. In the first part, the results of a SBM-WDEA model incorporated with undesirable outputs for different window widths were compared to determine the ideal window width. Then the efficiency scores for countries are presented based on ideal window width and in the last part, these results were compared with the efficiency scores of conventional models.

\subsection{SBM-WDEA with the ideal window width}

Table 1 shows the $D e v i_{i j}$ based on windows 1-10 and the minimum value for $D e v i_{i j}$ within 10 windows. As it can be seen the window 4 had the minimum Devi $i_{i j}$ in six years among the other windows. Therefore window 4 was selected as the ideal window width in this study and the efficiency scores of EU-27 countries during 2008 and 2017 based on the ideal window width are presented in Table 2. During 2008 and 2017, there were four high-efficiency countries including Greece, Spain, Italy and Malta with the average efficiency score higher than 0.90. The standard deviation (SD) of efficiency score during the studied period was estimated to be $0.057,0.074,0.032$ and 0.087 for Greece, Spain, Italy and Malta, respectively. The lower SDs implied the stable situation of the crop production sector in the most efficient countries. The lowest efficiency scores were reported for Luxembourg, Slovakia, Slovenia and Latvia, with the average efficiency score less than 0.40 . The highest SDs were calculated as 0.193, 0.189, 0.186 and 0.176 for Finland, Ireland, Bulgaria and Cyprus, respectively, implying the unstable management situation in these EU countries. 


\section{$2^{\text {nd }}$ International Conference on}

\section{MANAGEMENT, ECONOMICS \& FINANCE}

\section{5-17 November 2019}

Table 1. The calculated values for Dev $v_{i j}$ and MinDev $v_{i j}$ for different window width (j) and year (i).

\begin{tabular}{ccccccccccccc}
\hline Year & Devi $_{i 1}$ & Devi $_{i 2}$ & Devi $_{i 3}$ & Devi $_{i 4}$ & Devi $_{i 5}$ & Devi $_{i 6}$ & Devi $_{i 7}$ & Devi $_{i 8}$ & Devi $_{i 9}$ & Devi $_{i 10}$ & MinDevij \\
\hline 2008 & 7.084 & 5.766 & $\mathbf{0 . 9 2 8}$ & $\mathbf{0 . 9 2 8}$ & 1.821 & 2.221 & 2.523 & 2.683 & 2.730 & 2.730 & 0.928 \\
2009 & 12.576 & 3.271 & 1.306 & $\mathbf{0 . 2 9 7}$ & 1.601 & 2.178 & 2.988 & 3.134 & 3.214 & 3.741 & 0.297 \\
2010 & $\mathbf{0 . 0 7 9}$ & $\mathbf{0 . 0 7 9}$ & 0.293 & 0.700 & 1.127 & 9.346 & 1.660 & 1.767 & 1.800 & 1.839 & 0.079 \\
2011 & 7.560 & 3.128 & 1.460 & $\mathbf{1 . 0 5 7}$ & 2.137 & 9.396 & 3.483 & 4.519 & 4.806 & 5.543 & 1.057 \\
2012 & 6.899 & 4.688 & 1.778 & $\mathbf{0 . 0 2 4}$ & 1.635 & 7.559 & 3.314 & 4.406 & 5.000 & 6.545 & 0.024 \\
2013 & 13.264 & 2.789 & $\mathbf{0 . 0 9 6}$ & 1.797 & 2.448 & 8.052 & 4.409 & 4.978 & 5.067 & 5.308 & 0.096 \\
2014 & 6.270 & 1.709 & 0.576 & $\mathbf{0 . 5 7 3}$ & 1.839 & 10.793 & 3.568 & 4.282 & 4.521 & 4.566 & 0.573 \\
2015 & 8.941 & 6.040 & 4.049 & 2.087 & $\mathbf{1 . 1 5 2}$ & 11.779 & 7.110 & 8.085 & 8.165 & 8.384 & 1.152 \\
2016 & 9.283 & 4.444 & 2.576 & $\mathbf{0 . 5 8 0}$ & 1.931 & 14.503 & 6.190 & 7.624 & 7.717 & 7.925 & 0.580 \\
2017 & 4.990 & 4.914 & 3.601 & 0.473 & $\mathbf{0 . 0 3 3}$ & 14.712 & 4.853 & 7.267 & 7.267 & 9.336 & 0.033 \\
\hline
\end{tabular}

Based on the results it was indicated that the most efficient and environment friendly countries in crop production sector are Greece, Spain, Italy and Malta. To evaluate the impact of treating undesirable outputs on the efficiency scores, the results of model 1 and 2 which are presented in Figure 1 can be compared. In model 1 the undesirable outputs were considered in the productivity assessment while in model 2, undesirable outputs were neglected. As it can be seen, there is a big difference between efficiency scores for Netherlands, Sweden, Finland, Czech Republic, Germany, France, and Austria when undesirable outputs are neglected (mode 2) and undesirable outputs are considered in the DEA model (mode 1). As it can be seen, for the most efficient countries including Italy, Spain, Greece, and Malta, equal efficiency scores were estimated for both model 1 and 2.

The Average efficiency scores for EU countries during 2008-2017 varied between 0.51 and 0.65 , where the least and the highest values were reported for 2009 and 2012, respectively (Table 2).

Table 2. Average efficiency scores of EU countries during 2008-2017 for the ideal window width.

\begin{tabular}{lccccccccccccc}
\hline Countries & 2008 & 2009 & 2010 & 2011 & 2012 & 2013 & 2014 & 2015 & 2016 & 2017 & Average & SD \\
\hline Belgium & 0.378 & 0.361 & 0.462 & 0.429 & 0.502 & 0.458 & 0.411 & 0.441 & 0.458 & 0.429 & 0.433 & 0.040 \\
Bulgaria & 0.646 & 0.515 & 0.628 & 0.848 & 1.000 & 1.000 & 0.544 & 0.588 & 0.767 & 1.000 & 0.753 & 0.186 \\
Cyprus & 0.906 & 0.891 & 0.723 & 0.887 & 0.584 & 0.644 & 0.383 & 0.712 & 0.657 & 1.000 & 0.739 & 0.176 \\
Czech Republic & 0.510 & 0.415 & 0.491 & 0.548 & 0.458 & 0.454 & 0.459 & 0.416 & 0.421 & 0.418 & 0.459 & 0.043 \\
Denmark & 0.459 & 0.367 & 0.502 & 0.496 & 0.569 & 0.496 & 0.494 & 0.480 & 0.430 & 0.486 & 0.478 & 0.050 \\
Germany & 0.389 & 0.367 & 0.378 & 0.376 & 0.446 & 0.429 & 0.413 & 0.419 & 0.426 & 0.432 & 0.408 & 0.026 \\
Greece & 1.000 & 1.000 & 1.000 & 0.979 & 0.973 & 0.833 & 1.000 & 0.902 & 0.896 & 1.000 & $\mathbf{0 . 9 5 8}$ & 0.057
\end{tabular}


$2^{\text {nd }}$ International Conference on

\section{MANAGEMENT, ECONOMICS \& FINANCE}

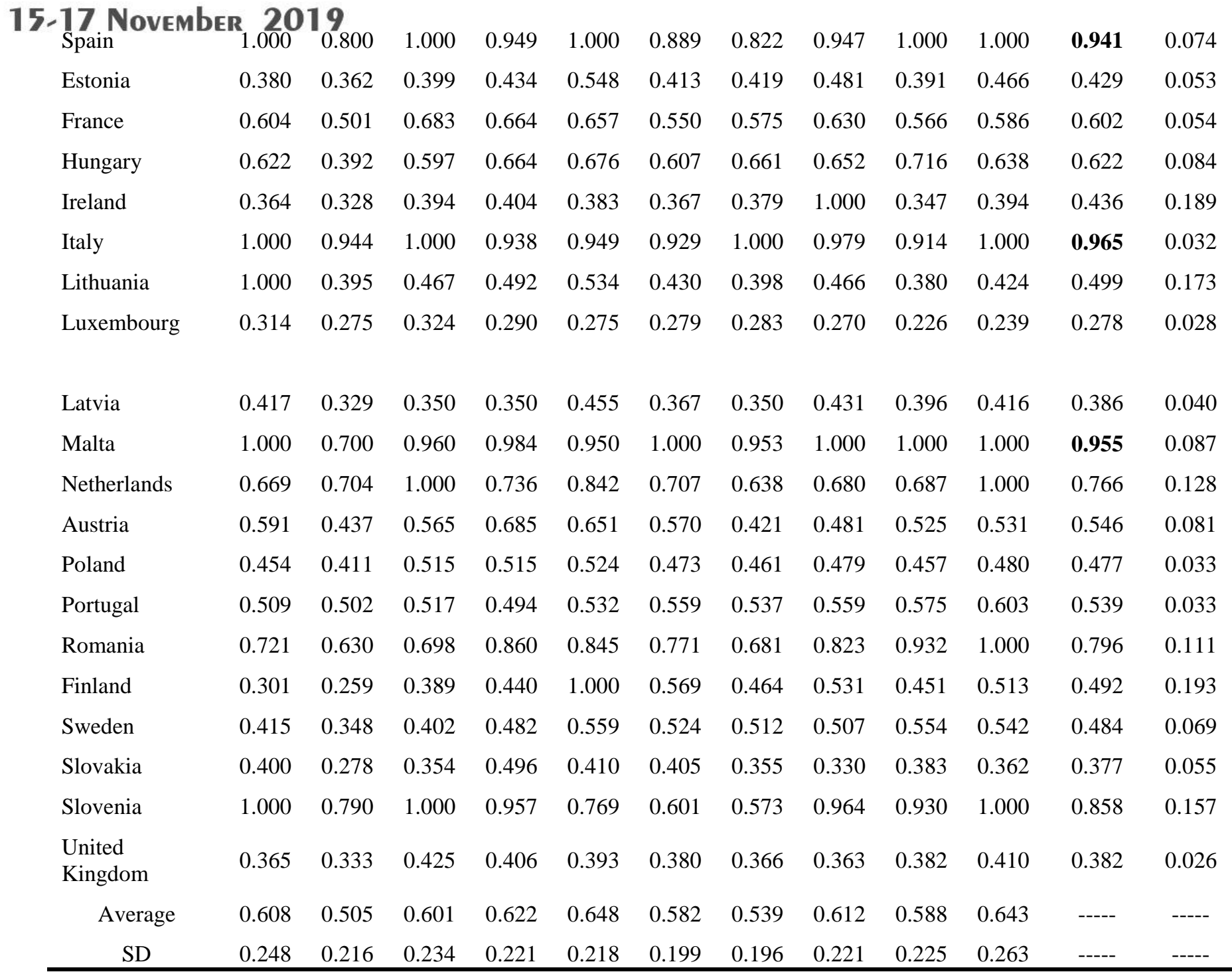

\subsection{Comparison of new and conventional DEA models}

In this section, two conventional DEA models including a SBM-WDEA model without considering undesirable outputs (called model 2) and a SBM-DEA model incorporated with undesirable outputs (without window analysis) (called model 3) were compared with a SBMWDEA model incorporated with undesirable outputs (called model 1). The results of these comparisons showed the lowest average efficiency score for model $1(0.60)$ and followed by model 3 (0.64) and model 2 (0.69). As it can be seen in Figure 1, the average efficiency score of each country during 2008 and 2017 were the lowest in model 1 while the majority of countries had the greatest efficiency scores in model 2. Lower efficiency scores from model 1 indicated that the this model can compare and evaluate the DMUs better than the models 2 and 3 (You \& Yan, 2011). The SD was calculated as $0.23,0.18$ and 0.25 for models 1,2 and 3 , respectively. The coefficient of variation $(\mathrm{CV})$ which is defined as the ratio of SD and the 


\section{$2^{\text {nd }}$ International Conference on \\ MANAGEMENT, ECONOMICS \& FINANCE}

\section{5-17 November 2019}

mean, showed equal variability among DMUs applying models 1 and $3(\mathrm{CV} \approx 0.39)$, while $\mathrm{CV}$ was calculated 0.26 for model 2 . The obtained efficiency scores from different models showed an almost equal ratio of DMUs were efficient based on model $1(12 \%)$ and $2(11 \%)$ while for model 3, around $29 \%$ of DMUs were determined as the efficient DMUs. This results confirmed that window analysis could estimate the efficiency of DMUs better that the non-window models. This finding was in agreement with the results obtained by Lin et al. (2018). Comparison of model 1 and 2 revealed that although the ratio of efficient DMUs was calculated equal for these models, the average efficiency score for model 1 was lower. This result indicated that by treating undesirable outputs in a W-DEA model, countries are compared and evaluated more accurately and the productivity is not overestimated. Due to the different nature of desirable and undesirable outputs, undesirable outputs should be distinguished in the DEA models, whereby both desirable and undesirable outputs are considered. The results of models 1 and 2 were in agreement with You and Yan (2011) and Hua, Bian, and Liang (2007) in which it was mentioned that disregarding the undesirable outputs in DEA models increases the estimated efficiency scores.

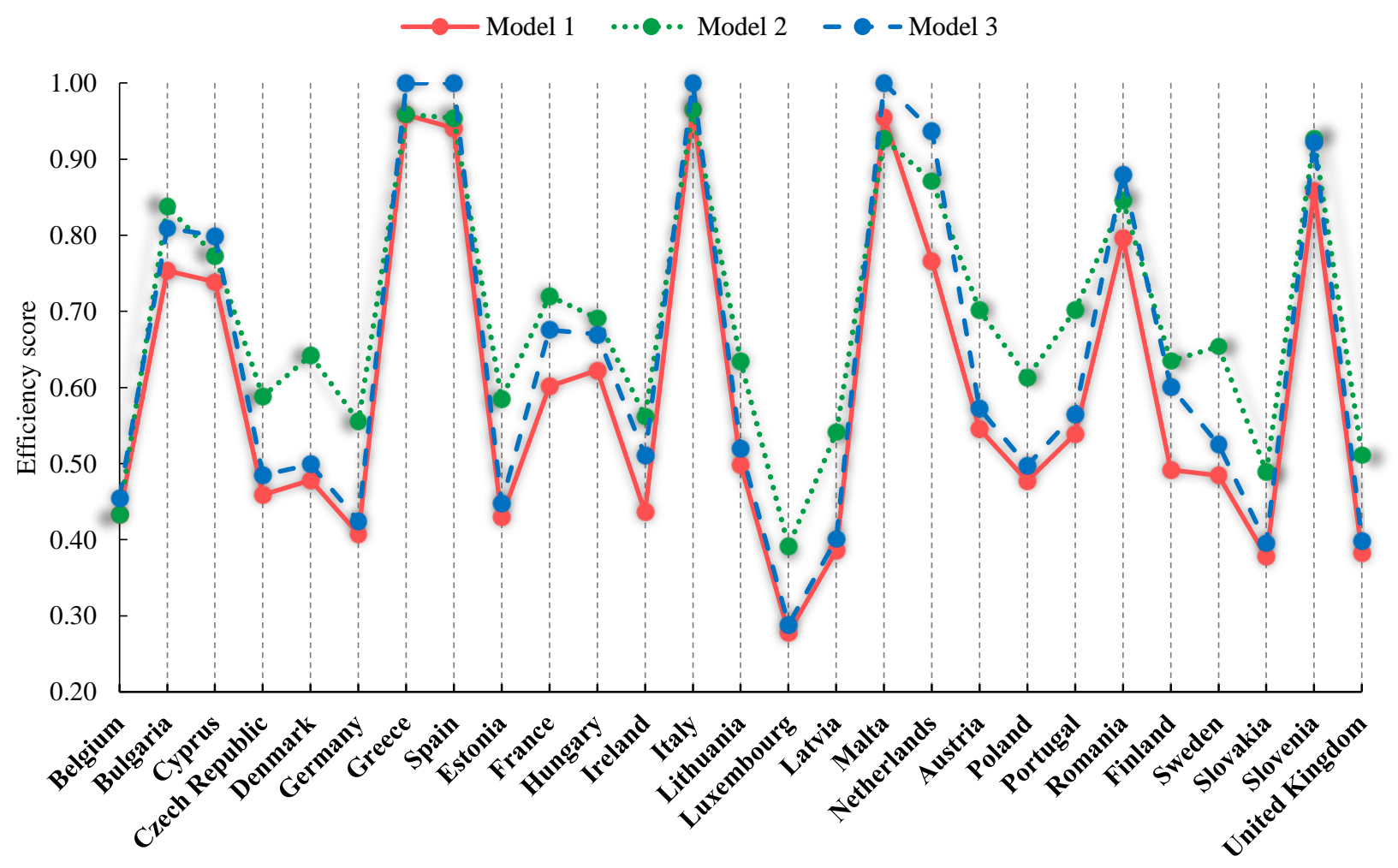

Figure 1. Comparison of the average efficiency scores in new (model 1) and conventional DEA models (model 2 and 3 ) for EU-27 countries. The models 1, 2 and 3 are SBM-WDEA model incorporated with undesirable outputs, SBM-WDEA model without considering undesirable output, and SBM-DEA model incorporated with undesirable outputs (without window analysis), respectively. 


\section{$2^{\text {nd }}$ International Conference on \\ MANAGEMENT, ECONOMICS \& FINANCE}

\section{5-17 November 2019}

\section{Conclusion}

In this study we applied a SBM-WDEA model incorporated with undesirable outputs for evaluating the crop production sector of 27 EU countries. Data of average input costs $\left(€ \mathrm{ha}^{-1}\right)$ (including fertilizer, protection, seed and other costs) as the model inputs, the gross domestic product $\left(€ \mathrm{ha}^{-1}\right)$ and the total GHG emissions $\left(\mathrm{kg} \mathrm{CO}_{2 \text {-eq }} \mathrm{ha}^{-1}\right)$ as the model desirable and undesirable outputs were collected from databases. The model with four windows was specified as the ideal window width by evaluating the efficiency scores of ten WDEA models. Obtained results for the model with ideal window width showed the higher efficiency scores for Spain, Greece, Italy and Malta. To evaluate the new model with the conventional ones, the results of a SBM-WDEA model incorporated with undesirable outputs was compared with a SBM-WDEA model without considering undesirable output, and a SBMDEA model incorporated with undesirable outputs (without window analysis). The results of this comparison showed the lowest average efficiency score for model 1. The SD was calculated as $0.23,0.18$ and 0.25 for models 1,2 and 3, respectively. Based on the obtained results it was concluded the model 1 can measure the efficiency scores of EU-27 countries more accurately and without overestimation. 


\section{$2^{\text {nd }}$ International Conference on \\ MANAGEMENT, ECONOMICS \& FINANCE}

\section{5-17 November 2019}

\section{Acknowledgment}

This research was carried out under the project entitled "Supporting the development of international mobility of research staff at CULS Prague" reg. no. CZ.02.2.69/0.0/0.0/16_027/0008366.

\section{References}

[1] Al-Refaie, A., Hammad, M., \& Li, M.-H. (2016). DEA window analysis and Malmquist index to assess energy efficiency and productivity in Jordanian industrial sector. Energy Efficiency, 9(6), 1299-1313.

[2] Asmild, M., Paradi, J. C., Aggarwall, V., \& Schaffnit, C. (2004). Combining DEA window analysis with the Malmquist index approach in a study of the Canadian banking industry. Journal of Productivity Analysis, 21(1), 67-89.

[3] Banker, R. D., Charnes, A., \& Cooper, W. W. (1984). Some models for estimating technical and scale inefficiencies in data envelopment analysis. Management science, 30(9), 1078-1092.

[4] Baráth, L., \& Fertő, I. (2017). Productivity and convergence in European agriculture. Journal of Agricultural Economics, 68(1), 228-248.

[5] Charnes, A., \& Cooper, W. W. (1984). Preface to topics in data envelopment analysis. Annals of Operations research, 2(1), 59-94.

[6] Charnes, A., Cooper, W. W., \& Rhodes, E. (1978). Measuring the efficiency of decision making units. European Journal of Operational Research, 2(6), 429-444.

[7] Cooper, W. W., Seiford, L. M., \& Tone, K. (2007). Introduction to data envelopment analysis and its uses: with DEA-solver software and references (Second Edition): Springer Science \& Business Media., Boston, MA.

[8] Dyckhoff, H., \& Allen, K. (2001). Measuring ecological efficiency with data envelopment analysis (DEA). European Journal of Operational Research, 132(2), 312325 .

[9] Edenhofer, O., Pichs-Madruga, R., Sokona, Y., Farahani, E., Kadner, S., Seyboth, K., ... Minx, J. C. (2014). Climate Change 2014: Mitigation of Climate Change. Contribution of Working Group III to the Fifth Assessment Report of the Intergovernmental Panel on Climate Change. (Vol. 3): Cambridge University Press, Cambridge, United Kingdom and New York, NY, USA.

[10]Emrouznejad, A., \& Yang, G.-1. (2018). A survey and analysis of the first 40 years of scholarly literature in DEA: 1978-2016. Socio-Economic Planning Sciences, 61, 4-8.

[11]European Commission. (2013). Overview of the CAP Reform 2014-2020. Agricultural Policy Perspectives Brief. Retrieved from https://ec.europa.eu/agriculture/sites/agriculture/files/policy-perspectives/policybriefs/05_en.pdf 


\section{$2^{\text {nd }}$ International Conference on}

\section{MANAGEMENT, ECONOMICS \& FINANCE}

15-17 Np2/AE Parliament, the Council, the European Economic and Social Committee and the Committee of the Regions. A policy framework for climate and energy in the period from 2020 to 2030. Retrieved from

[13]Eurostat. (2019). Greenhouse gas emissions by source sector (source: EEA). Retrieved from: Available

at: <https://ec.europa.eu/eurostat/web/agriculture/data/database?p_p_id=NavTreeportletpr od_WAR_NavTreeportletprod_INSTANCE_ff6jlD0oti4U\&p_p_lifecycle=0\&p_p_state $=$ normal\&p_p_mode $=$ view $\&$ p_p_col_id $=$ column $-2 \& p \_p \_c o l \_c o u n t=1>($ Last access: 08-10-2019).

[14]FADN. (2019). FADN public database during 2004-2017. Retrieved from: Available at:<https://ec.europa.eu/agriculture/rica/database/database_en.cfm > (Last access: 08-102019).

[15] Golany, B., \& Roll, Y. (1989). An application procedure for DEA. Omega, 17(3), 237 250.

[16] Hua, Z., Bian, Y., \& Liang, L. (2007). Eco-efficiency analysis of paper mills along the Huai River: An extended DEA approach. Omega, 35(5), 578-587.

[17] Kumbhakar, S. C., \& Lovell, C. A. K. (2003). Stochastic frontier analysis: Cambridge university press.

[18]Lin, S., Sun, J., Marinova, D., \& Zhao, D. (2018). Evaluation of the green technology innovation efficiency of China's manufacturing industries: DEA window analysis with ideal window width. Technology Analysis \& Strategic Management, 30(10), 1166-1181.

[19] Masuda, K. (2018). Energy efficiency of intensive Rice production in Japan: an application of data envelopment analysis. Sustainability, 10(1), 120.

[20] Mustapha, N. H. N., Aziz, A. A., \& Hashim, N. M. H. (2013). Technical efficiency in aquaculture industry using Data Envelopment Analysis (DEA) window: Evidences from Malaysia. Journal of Sustainability Science and Management, 8(2), 137-149.

[21]Peças, P., Götze, U., Bravo, R., Richter, F., \& Ribeiro, I. (2019). Methodology for Selection and Application of Eco-Efficiency Indicators Fostering Decision-Making and Communication at Product Level-The Case of Molds for Injection Molding. In M. Ram \& J. P. Davim (Eds.), Advanced Applications in Manufacturing Enginering (pp. 1-52): Woodhead Publishing, Elsevier.

[22] Pishgar-komleh, S. H., Zylowski, T., Rozakis, S., \& Kozyra, J. (2019). Efficiency under different methods for incorporating undesirable outputs in an LCA+DEA framework: A case study of winter wheat production in Poland. Journal of environmental management.

[23] Řepková, I. (2014). Efficiency of the Czech banking sector employing the DEA window analysis approach. Procedia Economics and Finance, 12, 587-596.

[24]Rizov, M., Pokrivcak, J., \& Ciaian, P. (2013). CAP subsidies and productivity of the EU farms. Journal of Agricultural Economics, 64(3), 537-557. 


\section{$2^{\text {nd }}$ International Conference on \\ MANAGEMENT, ECONOMICS \& FINANCE}

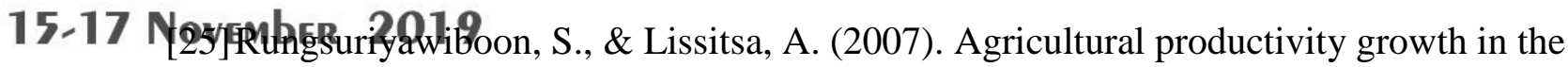
European Union and transition countries. In F. Fuller \& J. C. Beghin (Eds.), European Agriculture: Enlargement, Structural Change, CAP Reform and Trade Liberalization (Vol. 3, pp. 1-12): Nova Scienve Publisher, Inc. New York.

[26] Sardar Shahraki, A., Ali Ahmadi, N., \& Safdari, M. (2018). A New Approach to Evaluate the Economic Efficiency and Productivity of Agriculture Sector: The Application of Window Data Envelopment Analysis (WDEA). Environmental Energy and Economic Research, 2(3), 145-160.

[27] Vlontzos, G., Niavis, S., \& Manos, B. (2014). A DEA approach for estimating the agricultural energy and environmental efficiency of EU countries. Renewable and Sustainable Energy Reviews, 40, 91-96.

[28] Vlontzos, G., \& Pardalos, P. M. (2017). Assess and prognosticate green house gas emissions from agricultural production of EU countries, by implementing, DEA Window analysis and artificial neural networks. Renewable and Sustainable Energy Reviews, 76, 155-162.

[29] You, S., \& Yan, H. (2011). A new approach in modelling undesirable output in DEA model. Journal of the Operational Research Society, 62(12), 2146-2156. 